\title{
Propostas de Atividades com Tabelas em Livros Didáticos de Matemática dos Anos Iniciais do Ensino Fundamental do Brasil e do Quebec
}

\section{Activities Proposals with Tables in Mathematics textbooks from the Primary School from Brazil and Quebec}

\author{
Betânia Evangelista*a; Gilda Guimarães ${ }^{\text {b; }}$ Izabella Oliveira $^{c}$ \\ ${ }^{a}$ Universidade Federal de Pernambuco, Programa de Pós-Graduação Stricto Seusu em Educação Matemática e Tecnológica. PE, Brasil. \\ bUniversidade Federal de Pernambuco. PE, Brasil. \\ 'Université Laval. Canadá. \\ *E- mail: mbevangelista@hotmail.com
}

\begin{abstract}
Resumo
O livro didático é uma das principais fontes de consulta dos professores no ensino de estatística. Esse artigo analisa atividades envolvendo tabelas apresentadas nos livros didáticos de Matemática, dos anos iniciais do Ensino Fundamental do Brasil e do Quebec/CA. Nossas análises se fundamentaram em seis categorias: tipo de representação (quadro, banco de dados ou tabela); função da tabela; habilidade explorada; tipo de tabela (simples ou dupla entrada); tipo de variável; representação dos elementos fundamentais da tabela. Os resultados revelam que, em todos os anos de escolarização, podemos encontrar os três tipos de representação, sendo a maior frequência de tabelas em ambos os lugares de publicação. Além disso, a maioria delas é utilizada como objeto de estudo, indicando uma mudança recente de foco nos livros brasileiros, que priorizavam atividades na quais as tabelas eram pretexto para outros conceitos serem abordados. Observamos, entretanto, uma ênfase em interpretar e completar tabelas já estruturadas. Infelizmente, muitas tabelas não apresentam a fonte, principalmente nos livros do Quebec. A ausência de contextos reais e significativos não contribui efetivamente para a aprendizagem Estatística pelos alunos.
\end{abstract}

Palavras-chave: Livros Didáticos. Ensino de Estatística. Tabelas. Anos Iniciais

\begin{abstract}
Textbooks are one of the main sources of consultation for teaching statistics. This article analyzes activities involving tables presented in Primary School Mathematics textbooks from Brazil and from Quebec-CA. Our analysis were based on six categories: type of representation (rectangular configuration, database or table); table function; explored skill; table type (single or double entry); type of variable; representation of the fundamental elements of the table. The results show that in all years of schooling we can find the three types of representation, with the highest frequency of tables in both places of publication. Most of them are used as an object of study, indicating a recent change of focus in Brazilian books that prioritized activities in which tables were a pretext for other concepts to be addressed. However, we still observe an emphasis on interpreting and completing tables already structured. Unfortunately, many tables do not present their source, especially in Quebec textbooks. The absence of real data and significant contexts effectively does not contribute to the students' significant learning of Statistics.
\end{abstract}

Keyword: Textbook. Teaching of Statistics. Tables. Primary School.

\section{Introdução}

Nos últimos anos, as pessoas passaram a lidar com grandes quantidades de informações representadas em tabelas e gráficos. Tais representações são usadas para divulgar informações de forma resumida, buscando comunicar sobre crescimento populacional, mercado econômico, produção agrícola, taxa de desemprego, pesquisas eleitorais, situações relacionadas à saúde populacional, entre outros temas. Dessa forma, torna-se imprescindível que os cidadãos sejam capazes de compreender e analisar criticamente tais informações e que possam tomar decisões adequadas em função delas.

Nessa perspectiva, tem-se discutido bastante sobre a importância das tabelas para comunicar informações de interesses diversos na sociedade, bem como a necessidade de os cidadãos serem capazes de entender e analisar criticamente tais informações representadas para a tomada de decisões, conforme Gal (2002), Pereira e Conti (2011), Ponte, Brocardo e Oliveira (2009).

A partir da relevância da Estatística na sociedade, diversos países passaram a incluir seu ensino nas propostas curriculares $^{1}$. Por exemplo, no Brasil, em 2018, foi aprovado o novo documento curricular em vigor - Base Nacional Comum Curricular - BNCC (Brasil, 2018). No Quebec, a proposta curricular em vigor é o documento Programme de formation de l'école québécoise (Meq, 2006). Ambos os documentos introduzem o ensino de estatística desde os anos iniciais, valorizando tanto a elaboração e a realização de pesquisas pelos alunos, como a interpretação e a análise de pesquisas.

\footnotetext{
1 Como o foco desse artigo são os livros didáticos utilizados no Brasil e na parte francesa do Canada, ou seja, no Quebec, centraremos nossa análise sobre esses dois currículos.
} 
Para desenvolver o conjunto dessas habilidades estatísticas, vários autores propõem o uso do ciclo investigativo (Guimarães \& Gitirana, 2013; Silva \& Guimarães, 2013). Entre as fases que compõem esse ciclo, encontra-se a representação dos dados coletados, a qual é fundamental. É necessária uma organização ou uma classificação dos dados para que eles possam ser analisados permitindo, assim, a tomada de decisões.

De maneira mais específica, encontramos vários autores que abordam a importância da aprendizagem de tabelas em diferentes anos de escolarização (Martí, Sedano \& La Cerda, 2010; Gabucio, Martí, Enfedaque, Gilabert \& Konstantinidou, 2010; Conti \& Carvalho, 2011; Vanegas, 2013) e mais precisamente nos anos iniciais (Giot \& Quittre, 2008; Bivar \& Selva, 2013; Estrella, 2014; Guimarães \& Oliveira, 2014; Díaz-Levicoy, Morales \& Ortiz, 2017).

Entretanto, as tabelas não vêm sendo consideradas como objeto de ensino, mas sendo usadas como ferramentas para auxiliar na aprendizagem de outros conteúdos matemáticos, conforme afirmam Martí, Sedano e La Cerda (2010) e Estrella, Mena-Lorca e Olfos (2017).

Nesse mesmo sentido, Estrella (2014) afirma que, embora as tabelas sejam usadas para apresentar informações ou até mesmo como um recurso de transição para outro tipo de representação, não são apresentadas como objeto de estudo ou de pesquisa. Segundo a autora, isso é muito preocupante, pois interpretar dados em tabelas não é uma atividade fácil e, por consequência, a aquisição dessa habilidade, pelos alunos, não é transparente.

Essa abordagem, na qual as tabelas servem para ensinar outros conteúdos, é reforçada pelas atividades propostas em livros didáticos de Matemática do Ensino Fundamental no Brasil (Guimarães, Gitirana, Cavalcanti \& Marques, 2007; Pereira \& Conti, 2011; Bivar \& Selva, 2011; Curi \& Nascimento, 2016; Amorim \& Silva, 2016).

Diante dessa importância, e da necessidade do aprendizado da tabela, é preciso entender que situações de ensino possibilitam essa aprendizagem efetivamente. Logo, sabendo da importância dos livros didáticos para o ensino de Matemática, optamos por analisar quais são as propostas de atividades apresentadas neles.

Para fundamentar as análises sobre os livros didáticos, apresentaremos, em um primeiro momento, quais são as orientações propostas nos currículos do Brasil e do Québec.

\section{Orientações Curriculares para o Ensino de Tabelas no Brasil e no Quebec}

Segundo Amorim e Guimarães (2016), refletir sobre o currículo prescrito, ou orientações curriculares, se faz necessário, uma vez que eles influenciam diretamente no currículo apresentado, ou seja, nas propostas de atividades apresentadas nos livros didáticos, as quais passam a influenciar no cotidiano escolar até se tornarem efetivas em sala de aula.

No Brasil, quando os livros didáticos analisados foram publicados, estavam em vigor os Parâmetros Curriculares Nacional - PCNs (1997) ${ }^{2}$. Nesse documento, as orientações para o ensino de Estatística, denominadas de "Tratamento da Informação", afirmavam que os alunos deveriam desenvolver procedimentos para coletar, organizar, comunicar e interpretar dados utilizando tabelas, gráficos e outras representações que aparecem frequentemente em sua vida cotidiana. Para tal, os alunos deveriam ser levados a confrontar, avaliar e inferir sobre informações contidas em imagens que aparecem na mídia, tais como jornais e revistas.

Os PCNs defendiam que o ensino de Matemática devia ser associado com a observação do mundo real, por meio de representações (esquemas, tabelas, figuras, entre outras), as quais se conectam com princípios e conceitos matemáticos. Dessa forma, a tabela era abordada também como uma ferramenta para o ensino de outros conteúdos matemáticos, com um caráter intradisciplinar. Já na seção "Os conteúdos de Matemática no Ensino Fundamental", o trabalho com tabela é visto como um objeto de aprendizagem, deixando claro que tabelas e outras representações são formas de expor dados coletados em uma pesquisa. Salienta-se que o professor deve dar especial atenção à construção de tabelas, por meio de informações de fontes reais, além da valorização da linguagem oral e escrita como forma de comunicar as ideias obtidas a partir da interpretação de gráficos e tabelas. Além disso, defende que a leitura e interpretação de dados em tabelas deve permitir que os alunos percebam relações entre acontecimentos, façam previsões e evitem interpretações parciais e precipitadas.

Para sintetizar melhor as ideias presentes nos PCNs de Matemática para $1^{\circ}$ ciclo $\left(1^{\circ}, 2^{\circ}\right.$ e $3^{\circ}$ anos $)$ e $2^{\circ}$ ciclo $\left(4^{\circ}\right.$ e $5^{\circ}$ anos) do Ensino Fundamental (Brasil, 1997), no eixo Tratamento da Informação, elaboramos um quadro, no qual indicamos as habilidades, a partir dos conteúdos conceituais e procedimentos exclusivos, para a aprendizagem de tabelas por ciclo de escolaridade.

Quadro 1 - Orientações Curriculares das habilidades para aprendizagem de tabelas detalhadas por ciclo de escolarização, conforme os PCNs do Ensino Fundamental

\begin{tabular}{|l|c|c|}
\hline \multicolumn{1}{|c|}{ Conteúdos Conceituais e Procedimentos } & $\begin{array}{c}\mathbf{1}^{\mathbf{0}} \\
\text { Ciclo }\end{array}$ & $\begin{array}{c}\mathbf{2}^{\mathbf{0}} \\
\text { Ciclo }\end{array}$ \\
\hline Organizar informações (em tabela). & $\mathrm{X}$ & \\
\hline $\begin{array}{l}\text { Coletar, organizar e descrever informações } \\
\text { presentes em tabelas }\end{array}$ & $\mathrm{X}$ \\
\hline $\begin{array}{l}\text { Criar registros pessoais para comunicar } \\
\text { informações representadas (em tabelas). }\end{array}$ & $\mathrm{X}$ & \\
\hline
\end{tabular}

2 Atualmente, no Brasil, está em vigor o novo documento curricular - Base Nacional Comum Curricular - BNCC (Brasil, 2018). Entretanto, iremos apresentar unicamente as orientações propostas pelos Parâmetros Curriculares Nacional - PNCs (1997), pois as atividades, presentes nas coleções de livros didáticos brasileiros analisadas por nós, foram construídas conforme as orientações dos PCNs. 


\begin{tabular}{|l|c|c|}
\hline \multicolumn{1}{|c|}{ Conteúdos Conceituais e Procedimentos } & $\begin{array}{c}\mathbf{1}^{\mathbf{0}} \\
\text { Ciclo }\end{array}$ & $\begin{array}{c}\mathbf{2}^{\mathbf{0}} \\
\text { Ciclo }\end{array}$ \\
\hline $\begin{array}{l}\text { Interpretar tabelas simples e de dupla entrada } \\
\text { para entender a informação obtida. }\end{array}$ & $\mathrm{X}$ & $\mathrm{X}$ \\
\hline $\begin{array}{l}\text { Produzir textos escritos a partir da interpretação } \\
\text { de dados representados em tabelas. }\end{array}$ & $\mathrm{X}$ & \\
\hline $\begin{array}{l}\text { Produzir textos escritos a partir da interpretação } \\
\text { de dados representados em tabelas para a } \\
\text { identificação de características previsíveis e } \\
\text { aleatórias de acontecimentos. }\end{array}$ & $\mathrm{X}$ \\
\hline $\begin{array}{l}\text { Construir tabelas com base em informações } \\
\text { contidas em textos jornalísticos, científicos e } \\
\text { outros. }\end{array}$ & $\mathrm{X}$ \\
\hline
\end{tabular}

Fonte: Brasil (1997).

A partir desse quadro, percebemos que o trabalho com tabelas é proposto a partir das três habilidades elencadas anteriormente: interpretar, construir e comunicar, as quais são propostas durante todos os anos iniciais de escolarização. A gradação está presente nos aportes que auxiliam a exploração de tais habilidades, como fonte das informações.

Da mesma forma, um dos documentos que atua como referência para a elaboração dos currículos da Educação Básica no Quebec, é a "Progression des apprentissages: Mathématique" (MELS, 2009)³). Ele fornece, de maneira detalhada, os conceitos e processos que os alunos devem adquirir ao longo dos 6 anos do Ensino Primário (alunos de 5-12 anos). Além disso, especificamente no conteúdo "tabela", na seção dedicada a Estatística, o documento faz referência à necessidade de desenvolver o pensamento estatístico dos alunos a partir de atividades que os levem a representar dados em tabelas ou em gráficos de barras diversos, como pictogramas ou barras, assim como por meio do procedimento de interpretar ou comparar dados representados em tabela ou gráfico.

Ao longo dos 3 ciclos de escolarização, que correspondem aos 6 anos escolares do Ensino Primário ou Fundamental, sendo 2 anos por ciclo, observamos quatro temas ligados ao trabalho com tabelas, são eles: formular perguntas de pesquisa a partir de dados representados em uma tabela; coletar, descrever e organizar dados (classificar ou categorizar) usando tabelas; interpretar os dados usando uma tabela; e representar dados usando uma tabela. Todos esses conceitos e processos são sempre iniciados no primeiro ano de cada ciclo de aprendizagem, no qual os alunos devem aprender a fazer tais procedimentos com a ajuda do professor. Já no final do ciclo, ou seja, no segundo ano, os estudantes devem realizar sozinhos tais procedimentos ao final do ano letivo. A única exceção é o conceito e procedimento relacionado à representação de dados usando uma tabela, pois há a orientação, para o $3^{\circ}$ ciclo, de que os alunos devem reutilizar esse conhecimento.

Apresentamos, no Quadro 2, as ideias resumidamente presentes na "Progression des apprentissages:
Mathématique”, (MELS, 2009, pg. 24). O Quadro 2 aponta o que desenvolver e como exercitar os conceitos e processos para desenvolver a aprendizagem em tabelas por ano/ciclo de escolaridade.

Quadro 2 - Orientações Curriculares de conceitos e processos sistematizados para desenvolver a aprendizagem em tabelas por ano/ciclo de escolarização

\begin{tabular}{|c|c|c|c|c|c|c|}
\hline \multirow[b]{2}{*}{ Conceitos e Processos } & \multicolumn{2}{|c|}{$1^{\circ}$ ciclo } & \multicolumn{2}{|c|}{$2^{\circ}$ ciclo } & \multicolumn{2}{|c|}{$3^{\circ}$ ciclo } \\
\hline & $\begin{array}{c}1^{\circ} \\
\text { ano }\end{array}$ & $\begin{array}{c}2^{\circ} \\
\text { ano }\end{array}$ & $\begin{array}{c}3^{\circ} \\
\text { ano }\end{array}$ & $\begin{array}{c}4^{\circ} \\
\text { ano }\end{array}$ & $\begin{array}{c}5^{\circ} \\
\text { ano }\end{array}$ & $\begin{array}{c}6^{\circ} \\
\text { ano }\end{array}$ \\
\hline $\begin{array}{l}\text { 1. Formular perguntas de } \\
\text { pesquisa a partir de dados } \\
\text { representados em uma } \\
\text { tabela }\end{array}$ & & & & & & \\
\hline $\begin{array}{l}\text { 2. Coletar, descrever } \\
\text { e organizar dados } \\
\text { (classifique ou categorize) } \\
\text { usando tabelas }\end{array}$ & & & & & & \\
\hline $\begin{array}{l}\text { 3. Interpretar os dados } \\
\text { usando uma tabela }\end{array}$ & & & & & & \\
\hline $\begin{array}{lcc}\text { 4. } & \text { Representar } & \text { dados } \\
\text { usando uma tabela } & \end{array}$ & & & & & & \\
\hline $\begin{array}{l}\mathrm{O} \text { aluno aprende a fazer } \\
\mathrm{O} \text { aluno faz isso sozinh } \\
\mathrm{O} \text { aluno reutiliza esse } \mathrm{c}\end{array}$ & $\begin{array}{l}\text { sso cc } \\
\text { no fi } \\
\text { nheci }\end{array}$ & $\mathrm{ma}$ & r & $\begin{array}{l}\text { ção d } \\
\text { tivo. }\end{array}$ & & ssor. \\
\hline
\end{tabular}

O documento do Quebec não aponta os tipos de tabelas a serem explorados, o que nos parece uma distinção importante a ser feita em relação ao currículo brasileiro, diante da diferença de complexidade existente entre elas, conforme Martí, Sedano e La Cerda (2010). Assim como, os tipos de dados a serem explorados (variáveis) numa tabela não são sinalizados explicitamente no documento do Quebec.

A partir das informações apresentadas, podemos constatar que ambas as propostas curriculares para o ensino de tabela abordam habilidades, conceitos e procedimentos a serem aprendidos ao longo de cada ciclo de escolarização, o que é bastante positivo. No entanto, essas propostas ainda não são suficientes para criar uma gradação ou complexidade mais evidente entre os ciclos quanto à introdução de diferentes tipos de variáveis, ou até mesmo, o que de fato é construir ou representar. Logo, fica a cargo dos autores de livros didáticos e professores fazerem a introdução dos diversos elementos que compõem a aprendizagem de tabelas. Acrescentamos, ainda, ser fundamental e possível que os alunos tenham contato com tabelas que possuam mais de uma variável, visto que se deve relacionar informações diversas para a tomada de decisão, desde os primeiros anos de escolarização.

Assim como Brasil, a escolha dos livros didáticos no Quebec é realizada pelos professores, que definem quais livros irão utilizar em cada ano escolar. Ademais, os cadernos de atividades precisam estar de acordo com o documento curricular, conforme os brasileiros.

3 Optamos em analisar esse documento, especificamente, pois ele apresenta de forma mais completa as propostas curriculares presentes no Programme de formation de l'école québécoise (MEQ, 2006). 
É importante ressaltar que as escolas do sistema de ensino público no Brasil só podem adquirir livros didáticos que foram aprovados no Programa de Avaliação Nacional do Livro Didático - PNLD ${ }^{4}$.

\section{Estudos sobre Atividades com Tabelas em Livros Didáticos}

A aprendizagem de tabela é complexa e não se dá de forma imediata, conforme Martí, Sedano e la Cerda (2010), pois envolve a compreensão de diferentes habilidades que muitas vezes não são abordadas adequadamente ao longo da escolarização, de acordo com Bivar e Selva (2013). A aprendizagem de tabela só ocorre efetivamente quando essa se torna objeto de ensino, que por sua vez necessita de propostas de atividades, as quais busquem levar os alunos a refletir e compreender a função da tabela.

Nesse sentido, segundo Salcedo (2020), nos últimos anos, atividades com tabelas em livros didáticos do Ensino Fundamental vêm sendo objeto de estudo de diferentes pesquisadores que buscam analisar como as atividades são apresentadas em diferentes anos escolares. Estudos brasileiros (Guimarães, Gitirana, Cavalcanti \& Marques, 2007; Bivar \& Selva, 2011; Pereira \& Conti, 2011; Curi \& Nascimento, 2016; Evangelista \& Guimarães, 2019, entre outros) e estudos internacionais (Díaz-Levicoy, Morales, López-Martín \& RoaMunóz, 2015; Pallauta, Serrano \& Guerrero, 2019) analisam propostas de atividades com tabela em livros didáticos, usados por crianças na faixa etária de 6 a 13 anos. É importante ressaltar que não foi encontrado nenhum estudo realizado no Quebec em relação ao ensino e aprendizagem de tabelas no Ensino Fundamental.

Guimarães et al. (2007) analisaram todas as coleções aprovadas pelo PNLD de 2004 (17 coleções de livros didáticos de Matemática dos anos iniciais do Ensino Fundamental) e observaram que 56,4\% dessas atividades não explorava tabela como objeto de estudo e sim como forma de apresentar outros conteúdos matemáticos, como conversões de sistemas de numerações, sucessor e operações. Acrescido a isso, somente 2,5\% das atividades solicitava uma construção de tabelas pelos alunos. Esse uso de tabelas para aprendizagem de outros conceitos também foi observado por Pereira \& Conti (2011). Díaz-Levicoy et al. (2015) também observaram esse mesmo uso de tabelas em livros didáticos chilenos, e acrescentam o baixo percentual de atividades envolvendo a construção de tabelas pelos alunos.

Bivar e Selva (2011), analisando cinco coleções de livros didáticos de Matemática dos anos iniciais do Ensino Fundamental, classificaram, mais especificamente, as atividades envolvendo tabela e observaram que $62 \%$ solicitavam o preenchimento de dados de uma tabela já estruturada, 27\% envolviam interpretação, 10\% solicitavam a transformação da tabela para gráfico e vice-versa e, apenas $2 \%$ solicitavam uma construção de tabela.

Evangelista e Guimarães (2019), tendo como base o texto de Guimarães e Oliveira (2014), que ressalta uma indiferenciação entre Quadro, Banco de dados e Tabelas, analisam as atividades de 8 coleções de livros didáticos de Matemática do $1^{\circ}$ ao $5^{\circ}$ ano do Ensino Fundamental, aprovadas pelo PNLD de 2016. As autoras definem então:

- Quadro é uma configuração retangular com linhas e colunas que não expressam variáveis e, em geral, solicitam cálculos matemáticos.

- Banco de dados é uma configuração retangular com linhas e colunas que apresenta dados brutos. Nas linhas encontramos os elementos e nas colunas variáveis que vão descrevendo cada elemento, o que permite saber características correspondentes a cada uma das variáveis para cada elemento/sujeito.

- Tabela é uma configuração retangular com linhas e colunas, que apresenta dados sistematizados, pois não permite mais sabermos as informações individualizadas, como em um banco de dados. Apresenta categorias e sua frequência (absoluta ou relativa).

Nesse estudo, observam que as coleções didáticas denominam de tabela vários tipos de configurações retangulares. Acreditamos que essa indiferenciação pode gerar dificuldades para que alunos e professores compreendam o que é, de fato, uma tabela.

Assim, esse estudo buscou realizar uma análise das atividades que envolviam tabela em livros didáticos de Matemática dos anos iniciais do Ensino Fundamental, utilizados por alunos do Brasil e do Quebec ${ }^{5}$.

\section{Método}

Para atender o objetivo proposto, analisamos livros didáticos de Matemática, dos anos iniciais do Ensino Fundamental ${ }^{6}$, do Brasil e do Quebec, utilizados por crianças da faixa etária de 6 a 11 anos de idade. Foram exploradas 10 (dez) coleções brasileiras (volumes do $1^{\circ}$ ao $5^{\circ}$ ano), perfazendo 50 volumes aprovados pelo PNLD/2016 (Brasil, 2015). Diferentemente, no Quebec, os livros são organizados por ciclo. Assim, analisamos 4 coleções por ciclo de aprendizagem, ou seja, em cada ano escolar 4 livros, totalizando 20 volumes didáticos. Isso se deu porque

4 O PNLD avalia obras enviadas ao MEC, as quais, quando aprovadas, podem ser compradas e distribuídas pelas escolas públicas brasileiras em função das demandas dos professores em todos os níveis de escolaridade e áreas de conhecimento. De acordo com os dados divulgados pelo Fundo Nacional de Desenvolvimento da Educação - FNDE, em 2019, foram gastos aproximadamente R $\$ 616.000 .000,00$ para a compra de livros do $1^{\circ}$ ao $5^{\circ}$ ano do Ensino Fundamental, que foram distribuídos a alunos e professores de escolas públicas brasileiras. O MEC é disparado o maior comprador de livros no Brasil.

5 As análises foram realizadas com os livros didáticos utilizados apenas por alunos das escolas da Região do Quebec - Canadá. Lá, os materiais analisados por nós são denominados de caderno de saberes e atividades.

6 O Ensino Fundamental Brasileiro é composto por 9 anos sendo os anos iniciais composto por 5 anos $\left(1^{\circ}\right.$ ao $5^{\circ}$ ano $)$. No Quebec, o Ensino Fundamental ou Ensino Primário é composto por 6 anos de escolarização, $\left(1^{\circ}\right.$ ao $6^{\circ}$ ano). O ingresso das crianças ocorre no primeiro ano de ambos os locais com 6 anos de idade. 
as coleções não, necessariamente, apresentam volumes para todos os ciclos.

Para criar nossas categorias de análise, consideramos estudos anteriores como Guimarães, Gitirana, Cavalcanti e Marques (2007), Bivar e Selva (2011), Guimarães e Oliveira (2014); Díaz-Levicoy, Morales e Lópes-Martín (2015), Amorim e Silva (2016), e ainda Cazorla, Magina, Gitirana e Guimarães (2017), Evangelista e Guimarães (2017; 2019), Sepúlveda, Díaz-Levicoy e Jara (2018), García-García, DíazLevicoy, Vidal-Henry e Arredondo (2019), Pallauta, Serrano \& Guerrero (2019), Salcedo (2020).

Assim, as análises das atividades levam em consideração os aspectos quantitativos e qualitativos focadas em nossas 6 (seis) categorias. Contudo, todas as atividades foram analisadas em função da primeira categoria, a qual se refere ao tipo de representação. Já as demais categorias de análise referem-se somente às atividades com tabelas, de acordo com a nossa classificação realizada nessa primeira categorização.

- Tipo de representação: refere-se ao tipo de representação encontrada na atividade, podendo ser quadro, banco de dados e tabela.

- Função da tabela: considera a tabela como instrumento que ajuda a ensinar outros conteúdos, ou como objeto de ensino.

- Habilidade explorada na tabela: consiste na atividade que é solicitada ao aluno, podendo ser: interpretar dados presentes em tabelas, completar dados representados numa tabela, transpor dados entre representações, conceituar uma tabela e construir tabela.

- Tipo de tabela: remete aos tipos de tabela explorados nas atividades: simples ou de dupla entrada.

- Ttipo de variável apresentada na tabela: qualitativa (nominal e ordinal) e quantitativa (discreta ou contínua).

- Representação dos elementos fundamentais da tabela: título, nome das variáveis/descritor, fonte (reais e fictícias).

\subsection{Resultados}

Foram encontradas 985 atividades nos livros brasileiros e 284 nos livros do Quebec. Analisando essas atividades, de acordo com a classificação adotada por nós para classificar quadro, banco de dados e tabela, identificamos que em todos os livros didáticos existem atividades que exploram essas três representações. Entretanto, é preciso ressaltar que a nomenclatura utilizada nesses livros não corresponde, necessariamente, a nossa classificação. Além disso, essas representações são encontradas em todos os anos de escolarização de ambos os lugares de publicação (Quadro 3).

Quadro 3 - Percentual de atividade por tipo de representação em função do ano escolar

\begin{tabular}{|c|c|c|c|c|c|c|}
\hline Representação & \multicolumn{2}{|c|}{ Quadro } & \multicolumn{2}{|c|}{ Banco de Dados } & \multicolumn{2}{|c|}{ Tabela } \\
\hline $\begin{array}{c}\text { Lugar } \\
\text { Ano }\end{array}$ & Brasil & Quebec & Brasil & Quebec & Brasil & Quebec \\
\hline $1^{\circ}$ ano & 4,5 & 2,7 & 21,1 & 32,4 & 74,4 & 64,9 \\
\hline $2^{\circ}$ ano & 8,4 & 5,7 & 28,0 & 22,9 & 63,6 & 71,4 \\
\hline $3^{\circ}$ ano & 6,6 & 11,1 & 31,9 & 30,6 & 61,5 & 58,3 \\
\hline $4^{\circ}$ ano & 4,2 & 10,7 & 43,9 & 40,5 & 51,9 & 48,8 \\
\hline $5^{\circ}$ ano & 7,9 & 14,3 & 38,0 & 33,9 & 54,1 & 51,8 \\
\hline
\end{tabular}

Fonte: Dados da pesquisa.

Observa-se que, em todos os anos escolares, as atividades com a representação Quadro são menos frequentes que os demais tipos. Na Figura 1, apresentamos um exemplo de atividade com essa representação. Nela, é solicitada aos alunos a realização de operações de subtração, tendo como contexto um "jogo".

Figura 1 - Exemplo de atividade com a representação quadro Pensando sobre o jogo Caetano brincou de jogo da gastança. Veja suas jogadas:

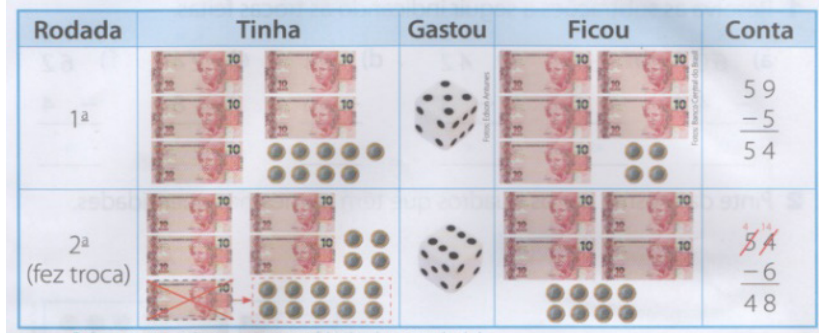

Fonte: Coleção 5 br - $3^{\circ}$ ano, p. 135
Em relação à representação banco de dados, observase na Tabela 1 uma frequência semelhante em todos os anos escolares, com um percentual entorno de 30\%. Essa tendência ocorre tanto nos livros brasileiros quanto nos do Quebec. Ressaltamos que nenhuma das atividades analisadas nomeia alguma representação como banco de dados. Para os autores das coleções, de ambos os lugares, quase todas as representações são tabelas, independentemente de sua função ou caracterização. Tal situação é vista também nos estudos de Amorim e Silva (2016) e Evangelista e Guimarães (2017; 2019).

Conforme o exemplo da Figura 2, temos uma atividade com a representação banco de dados que não foi nomeado como tal. Nela, os alunos preenchem o banco de dados a partir de um levantamento sobre brinquedos. 
Figura 2 - Exemplos de atividades com a representação banco de dados

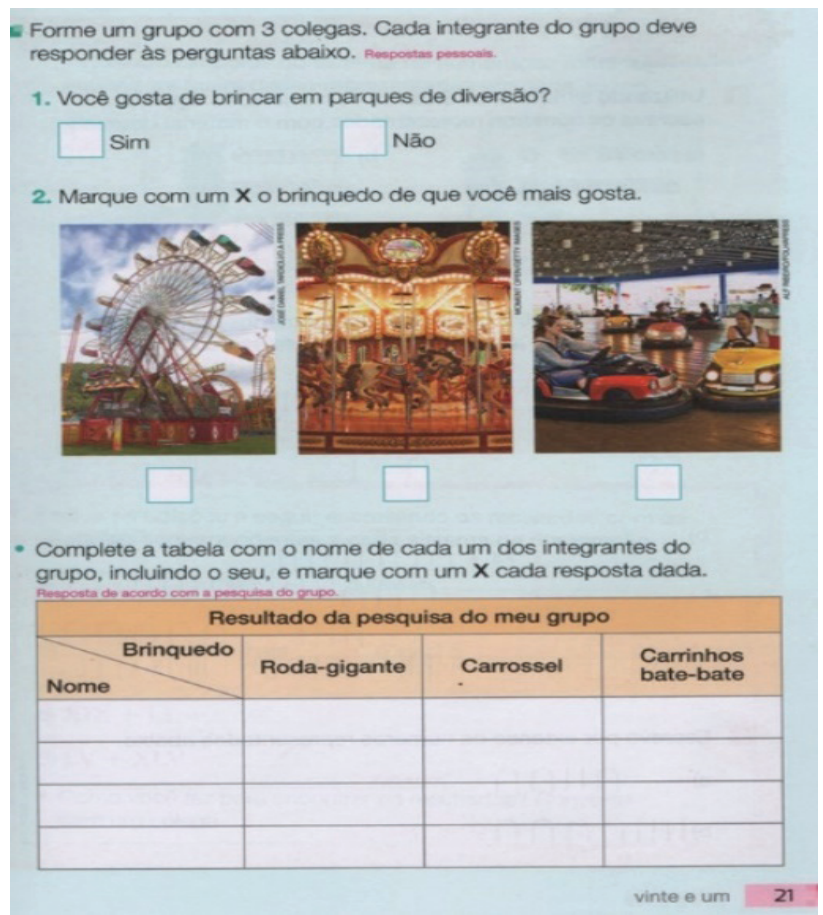

Fonte: Coleção $10 \mathrm{br}, 3^{\circ}$ ano, p. 21

Ainda no Quadro 3, observa-se que o maior quantitativo de atividades envolve tabelas para todos os anos escolares, com uma discreta diminuição do quantitativo nos anos finais, em ambos os locais. Esse predomínio de tabelas foi observado também nos estudos realizados por Evangelista e Guimarães (2017, 2019), os quais utilizaram essa mesma classificação. No exemplo da Figura 3, são mostradas informações sobre uma quantidade de livros, organizada por gênero literário, na biblioteca de uma escola. Aos alunos, então, é solicitada a interpretação dos dados representados.

Figura 3 - Exemplo de atividade com a representação banco de dados

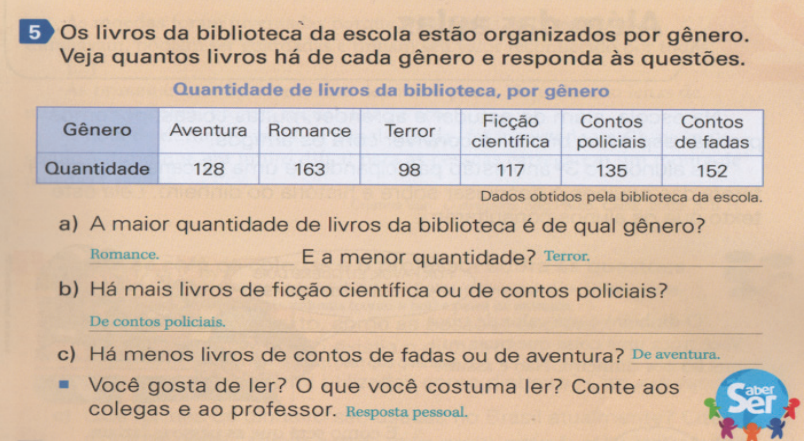

Fonte: Coleção $7 b r, 3^{\circ}$ ano, p. 31

Como relatamos anteriormente, nossa primeira categoria de análise, tipo de representação, envolve todas as atividades selecionadas. Entretanto, a partir desse momento, iremos apresentar e discutir os dados das demais categorias em função das 743 atividades que, de fato, exploravam a representação tabela, sendo que 582 são encontradas nos livros didáticos do Brasil e 161 são do Quebec.
Para a análise, em relação a função da tabela, categorizamos as atividades em que a tabela é objeto de estudo ou uma forma de apresentar outros conteúdos matemáticos. Observamos a distribuição percentual das atividades com tabelas em função do uso delas, ao longo dos anos de escolarização, e do lugar de publicação das coleções didáticas (Quadro 4).

É possível verificar comportamentos bem distintos entre os locais. Nos livros do Quebec, faz-se uso de tabelas como objeto da aprendizagem na grande maioria das atividades. Embora, o $5^{\circ}$ ano apresente um decréscimo em comparação aos demais, esse pode ser justificado em função da introdução de conteúdos como média aritmética e porcentagem, associados ou não aos gráficos circulares, conforme orientação curricular da região. Nos livros brasileiros, há uma maioria de atividades com foco na tabela como objeto de ensino, que vai decrescendo com o passar dos anos escolares. Porém, ao contrário dos livros do Quebec, ainda existe uma grande quantidade de atividades nas quais a tabela é uma forma de apresentar outros conteúdos.

Quadro 4 - Percentual de atividade de tabela por foco, ano escolar e lugar de publicação

\begin{tabular}{|c|c|c|c|c|}
\hline Função & \multicolumn{2}{|c|}{$\begin{array}{c}\text { Forma de } \\
\text { Apresentação }\end{array}$} & \multicolumn{2}{c|}{ Objeto de Estudo } \\
\hline $\begin{array}{c}\text { Lugar } \\
\text { Ano }\end{array}$ & Brasil & Quebec & Brasil & Quebec \\
\hline $1^{\mathbf{o}}$ ano & 35,8 & 4,2 & 64,2 & 95,8 \\
\hline $2^{\mathbf{o}}$ ano & 41,2 & 4,0 & 58,8 & 96,0 \\
\hline $3^{\circ}$ ano & 46,6 & 11,9 & 53,4 & 88,1 \\
\hline $4^{\circ}$ ano & 48,4 & 2,4 & 51,6 & 97,6 \\
\hline $5^{\circ}$ ano & 51,6 & 27,6 & 48,4 & 74,4 \\
\hline
\end{tabular}

Fonte: Dados da pesquisa

Apresentamos, na Figura 4, um exemplo de atividade na qual a tabela é uma forma de representação, uma vez que a atividade solicita aos alunos a identificação de sólidos geométricos para serem contados e registrados em uma tabela já estruturada, tendo como foco os conceitos geométricos. Já na Figura 5, a atividade requer interpretação de dados da tabela. Assim, o foco é na tabela como forma de análise das informações apresentadas.

Figura 4 - Atividade em que a tabela não é o objeto de aprendizagem

(1) Juliana montou um castelo com os sólidos de sua coleçáa. Descubra e registre na tabela quantos såo os solidos que compdem a figura abaixo.
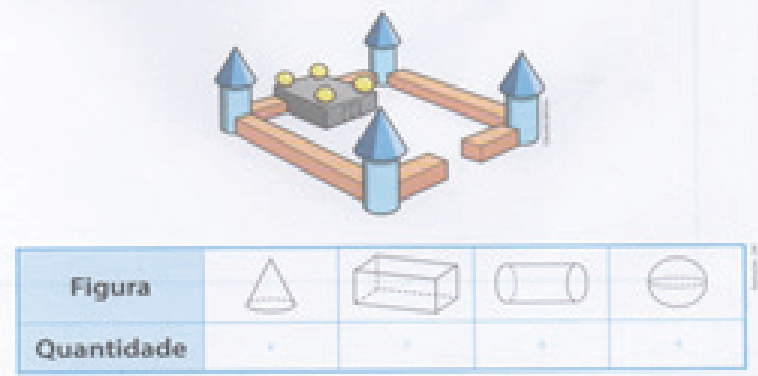

Fonte: Coleção 5br, $2^{\circ}$ ano, p. 95 
Figura 5 - Atividade em que a tabela é o objeto de aprendizagem 6. Na tabela está indicada a quantidade de microcomputadores com acesso à internet nos domicílios da Regiāo Nordeste do Brasil.
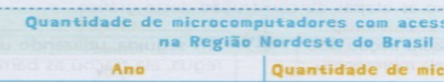

2008

2008

2009

2011

2012

Quantidade de micro

1743953 - $740000-20$

21606642160

340181734015

41585504158

) De acordo com a tabela, qual foi o ano com a maior quantidade de microcomputadores com acesso aे internet?

b) Em que ano houve a menor quantidade de microcomputadores com acesso à internet? 2008

C) Arredonde a quantidade de microcomputadores indicada na tabela centena mais próxima. Resposta na tabela

Fonte: Coleção $7 \mathrm{br}, 4^{\circ}$ ano, p. 133

Esses resultados são positivos, dado que demostram que as propostas de atividade encontradas nos livros didáticos focam a tabela como conteúdo que precisa e deve ser aprendido por alunos dos anos iniciais do Ensino Fundamental. Como afirma Lahanier-Reuter (2003), as tabelas são atividades comuns no ensino e precisam de aprendizado reflexivo desde os estágios iniciais da escola, pois, nem sempre, os métodos de elaboração das tabelas, ou de sua leitura, são dominados no ensino da estatística descritiva (onde as tabelas são onipresentes).

Esse resultado deve ser enfatizado, porquanto evidencia uma mudança importante nos livros didáticos brasileiros. No entanto, pesquisas anteriores (Guimarães, Gitirana, Cavalcanti \& Marques, 2007; Curi \& Nascimento, 2016; Amorim \& Silva, 2016) evidenciavam exatamente o contrário, ou seja, a predominância de atividades envolvendo tabelas como forma de apresentação de outros conteúdos. Essa mudança de postura dos livros didáticos, com relação a função da tabela, pode estar relacionada às constantes evoluções de orientações apresentadas nos últimos guias do PNDL (Amorim e Guimarães, 2016).

Ao analisarmos as habilidades exploradas nas tabelas, classificamos em: interpretar os dados, completar dados representados numa tabela, transpor dados entre representações, conceituar uma tabela e construir uma tabela. Apresentamos, na Tabela 3, os cinco tipos encontrados em função dos anos escolares.

Quadro 5 - Percentual de atividade com tabela por habilidade em função do ano escolar e lugar de publicação

\begin{tabular}{|c|c|c|c|c|c|c|c|c|c|c|}
\hline Habilidade & \multicolumn{2}{|c|}{ Interpretar } & \multicolumn{2}{c|}{ Completar } & \multicolumn{2}{c|}{ Transpor } & \multicolumn{2}{c|}{ Conceituar } & \multicolumn{2}{c|}{ Construir } \\
\hline $\begin{array}{c}\text { Lugar } \\
\text { Ano }\end{array}$ & BRA & QUE & BRA & QUE & BRA & QUE & BRA & QUE & BRA & QUE \\
\hline $1^{\circ}$ ano & 26,9 & 41,7 & 55,2 & 20,8 & 17,9 & 20,8 & 0 & 16,7 & 0 & 0 \\
\hline $2^{\circ}$ ano & 35,3 & 20,0 & 41,2 & 20,0 & 22,0 & 40,0 & 0 & 20,0 & 1,5 & 0 \\
\hline $3^{\circ}$ ano & 50,4 & 23,7 & 32,8 & 33,3 & 14,5 & 31,2 & 0 & 11,8 & 2,3 & 0 \\
\hline $4^{\circ}$ ano & 60,5 & 17,1 & 14,5 & 36,6 & 16,2 & 39,0 & 0 & 7,3 & 2,8 & 0 \\
\hline $5^{\circ}$ ano & 63,7 & 51,7 & 17,7 & 10,3 & 14,6 & 24,2 & 0 & 10,4 & 4,0 & 3,4 \\
\hline
\end{tabular}

Fonte: Dados da pesquisa

Para a habilidade de interpretar dados em tabelas, constatamos que as coleções didáticas do Brasil apresentam uma progressão à medida que a escolarização avança, chegando a ter, nos últimos anos, mais de $60 \%$ das atividades encontradas. Já nas coleções do Quebec, há uma variação, entre os anos escolares, que independe da escolaridade.

No que se refere a completar dados representados numa tabela, constatamos uma progressão decrescente, em função da escolaridade, nos livros brasileiros. Já, nos livros do Quebec, novamente não há uma ordem no quantitativo entre os anos escolares. Entretanto, observa-se um quantitativo bem inferior para as do Quebec em relação ao $1^{\circ}$ e $2^{\circ}$ anos e superior em relação ao $4^{\circ}$ ano. Dessa forma, os livros apresentam diferenças em função do local no qual são produzidos e utilizados.

Abaixo, temos dois exemplos de atividade: um com a habilidade de interpretar dados presentes em tabelas (Figura 6) e outro (Figura 7) ${ }^{7}$, de completar dados em uma tabela, pois apresenta uma tabela quase pronta, restando aos alunos realizar a contagem de cada descritor, referente ao esporte preferido, e registrá-los nos locais correspondentes.
Figura 6 - Exemplo de atividade de interpretar em tabela 6. Uma fábrica fez um levantamento para saber a quantidade de peças produzidas em cada trimestre.

$$
\begin{aligned}
& \begin{array}{|l|l|l|l|}
\hline \text { v" trimestre } & 2 v \text { trimestre } & \text { 3n trimestre } & 4^{4} \text { erimestre } \\
\hline
\end{array} \\
& \begin{array}{c|c|c|c|c|c|}
\hline \begin{array}{c}
\text { Quantidade } \\
\text { de pecas }
\end{array} & 9850 & 10250 & 9500 & 10300 \\
\hline
\end{array} \\
& \text { De acordo com as dados acima, responda. } \\
& \text { a) Qual foi o trimestre em que essa fábrica produziu mais peças? as trimestre } \\
& \text { Quantas peças foram produzidas nesse trimestre? } 10300 \text { pecas } \\
& \text { b) Quais são os meses que correspondem ao trimestre em que a fábrica pro- } \\
& \text { c) Quais são os meses que correspondem aos trimestres em que a fábrica } \\
& \text { produziu entre } 9000 \text { e } 10000 \text { peças? janciro fevereiro, marcso jutho, agosto e setembro } \\
& \text { d) Ouantas peças, em média, essa fábrica produziu por trimestre? } 9975 \text { peras }
\end{aligned}
$$

Fonte: Coleção $7 \mathrm{br}, 4^{\circ}$ ano, p. 88

Figura 7 - Exemplo de atividade de completar dados da tabela 26 On pose la question suivante à des élèves de $3^{\circ}$ année: "Quel est votre sport préféré? » Les résultats sont notés dans le tableau de données suivant.

a) Complète la troisième ligne du tableau.

\begin{tabular}{|l|c|c|c|c|}
\hline \multicolumn{3}{|c|}{ Sport préfere des elèves de $3^{\circ}$ année } \\
\hline Sport & Soccer & Natation & Baseball & Tennis \\
\hline Compilation & HIH HII & HII II & III & I \\
\hline Nombre d'élèves & & & & \\
\hline
\end{tabular}

Fonte: Coleção $11 \mathrm{qb}, 3^{\circ}$ ano, p. 116

7 Tradução: Fazemos a seguinte pergunta aos alunos do $3^{\circ}$ ano: Qual é o seu esporte favorito? Os resultados são anotados na tabela do ano seguinte. Complete a terceira linha da tabela. 
Quanto a transpor dados entre representações, constatamos que as coleções didáticas do Quebec exploram bem mais esse tipo de habilidade do que as do Brasil (Figura $8^{8}$ ). Porém, em sua grande maioria, as atividades solicitam trocas de alguns dos dados entre as representações, independente do lugar de publicação. Chama nossa atenção o fato de que poucas foram as atividades encontradas que, realmente, solicitavam aos alunos a construção da representação (Figura 9).

Figura 8 - Atividade de transformar uma tabela em gráfico (parcial)

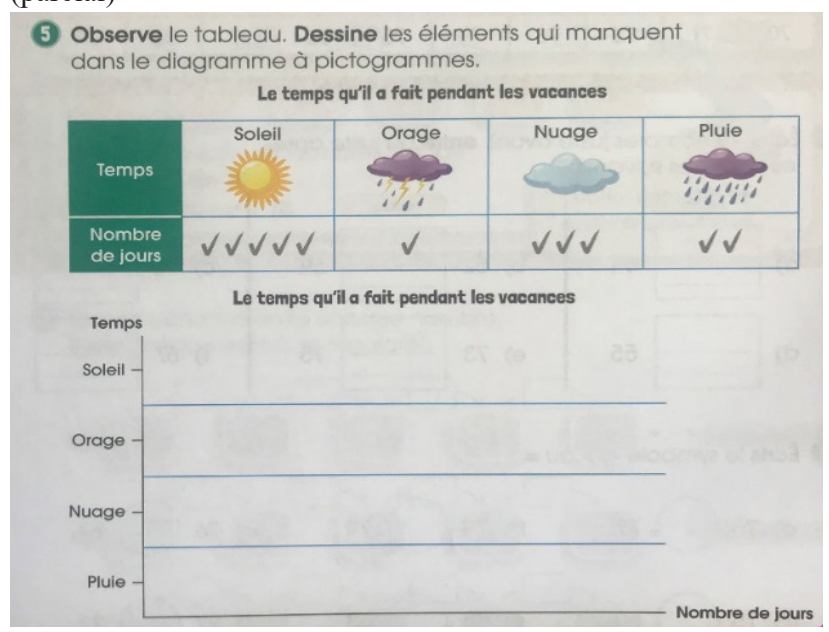

Fonte: Coleção $2 \mathrm{qb}, 1^{\circ}$ ano, p. 15

Figura 9 - Atividade de transformar uma tabela em gráfico (completa)

5. Se você fosse fazer uma vitamina com duas frutas diferentes entre:
abacate, banana, mamão e morango, quais frutas você escolheria?
Faça uma pesquisa sobre esse assunto com seus colegas e registre as
respostas em uma tabela como a apresentada abaixo. Para isso, copie a
tabela em seu caderno.
\begin{tabular}{|c|c|}
\hline \multicolumn{1}{|c|}{ Vitamina preferida } \\
\hline Frutas & Quantidade de pessoas \\
\hline Abacate e banana & \\
\hline Abacate e mamăo & \\
\hline Abacate e morango & \\
\hline Banana e mamăo & \\
\hline Banana e morango & \\
\hline Mamão e morango & \\
\hline
\end{tabular}

De acordo com o resultado de sua pesquisa, responda. Pessoa

a ) Quantas pessoas participaram da pesquisa?

b) Qual é a vitamina preferida dos seus colegas?

c) Quantas pessoas escolheram vitamina com morango? E quantas escolheram vitamina sem banana?

d) Construa um gráfico de barras em seu caderno a partir dos dados obtidos.

Fonte: Coleção 1 br, $4^{\circ}$ ano, p. 189

O exemplo da Figura 8 é um tipo de atividade que foi observado também por Bivar e Selva (2011), as quais argumentam que o aluno não é levado a aprender sobre a representação tabela, pois elas já vêm estruturadas, cabendo a eles apenas completar com os números.

Como observado, as habilidades de interpretar, completar e transpor dados entre representações são mais frequentes. Essa tendência ocorre em ambos os lugares de publicação. Resultados semelhantes foram vistos nos estudos de
Guimarães, Gitirana, Cavalcanti e Marques (2007), Bivar e Selva (2011), Evangelista e Guimarães (2019), García-García, Díaz-Levicoy, Vidal-Henry e Arredondo (2019) e, ainda, Díaz-Levicoy, Vásquez e Molina-Portillo (2018).

A habilidade de apresentar a conceitualização do que é uma tabela só foi encontrada em livros didáticos do Quebec. Nesses casos, os autores têm a preocupação de apresentar uma tabela e seus elementos no início da sessão estatística, principalmente, nos primeiros anos de escolarização. $\mathrm{Na}$ Figura 10, temos um exemplo dessa habilidade explicando os determinantes da representação em tabela como sua função, título, descritores e dados correspondentes.

Figura 10 - Exemplo que explora a habilidade de explicar o que é uma tabela

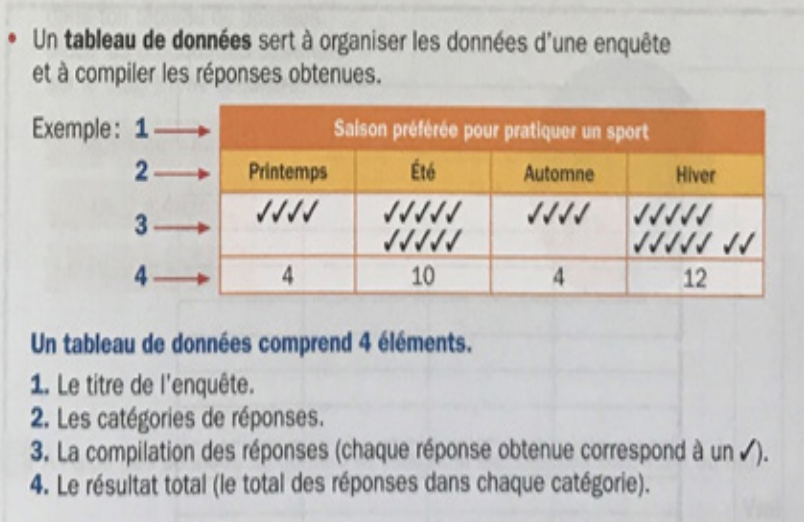

Fonte: Coleção 5 qb, $6^{\circ}$ ano, p. 17

Por fim, temos a habilidade de construir tabela. Infelizmente, nem nos livros brasileiros e nem nos do Quebec encontramos uma preocupação dos autores em propor a aprendizagem por parte dos alunos. Essa parece ser uma tendência das coleções didáticas em diferentes países, como México, Chile e Brasil, pois situação semelhante foi vista em estudos realizados por Guimarães, Gitirana, Cavalcanti e Marques (2007), Bivar e Selva (2011), Díaz-Levicoy, Morales, López-Martín e Roa-Munóz (2015), Amorim e Silva (2016), Evangelista e Guimarães (2017; 2019), DíazLevicoy, Vásquez e Molina-Portillo (2018), García-García, Díaz-Levicoy, Vidal-Henry e Arredondo (2019), Pallauta, Serrano e Guerrero (2019). Porém, como mostram Pontes e Guimarães (2019), alunos, desde o $3^{\circ}$ ano de escolaridade, já foram capazes de construir tabelas simples e de dupla entrada, quando estimulados.

$\mathrm{Na}$ Figura 11, temos uma atividade que requer dos alunos a construção da representação tabela. É possível observar que a atividade envolve uma pesquisa e solicita que os alunos elaborem uma tabela para registrar os dados. Entretanto, nenhuma instrução é apresentada, cabendo aos alunos construírem, se souberem, ou orientado pelo professor. 
Figura 11 - Exemplo de atividade de construir uma tabela Forme uma equipe com mais dois colegas.

Façam uma pesquisa na sua classe sobre a seguinte questão:

$$
\text { Para qual time de futebol você torce? }
$$

Selecionem os 5 times mais votados. No caderno, façam uma tabela registrando o número de votos para cada time. Depois, em papel quadriculado, construam um gráfico de barras, que deve ser recortado e colado no caderno.

Observem o gráfico, escrevam duas ou três perguntas e deem as respostas.

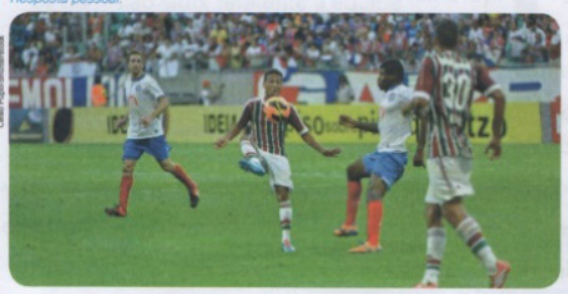

Partida de futebol entre Bahia e Fluminense, na Arena Fonte Nova,

Fonte: Coleção 1 br, $5^{\circ}$ ano, p. 112

Quanto à categoria Tipo de tabela, é possível observar que as tabelas simples, ou seja, as que exibem apenas uma única variável, são as mais frequentes para todos os anos de escolarização, independente do lugar de publicação das coleções (Quadro 6). Por outro lado, as tabelas de dupla entrada, ou seja, tabelas com mais de uma variável, vêm sendo pouco trabalhadas pelos livros didáticos, independente do ano de escolarização. Nos livros didáticos do Brasil, esse tipo de tabela começa a aparecer com maior frequência a partir do $3^{\circ}$ ano e no Quebec só no $5^{\circ}$ ano.

Quadro 6 - Percentual de atividade por tipo de tabela, ano escolar e lugar de publicação

\begin{tabular}{|c|c|c|c|c|}
\hline $\begin{array}{c}\text { Tipo de } \\
\text { tabela }\end{array}$ & \multicolumn{2}{|c|}{ Simples } & \multicolumn{2}{c|}{ Dupla entrada } \\
\hline $\begin{array}{c}\text { Lugar } \\
\text { Ano }\end{array}$ & Brasil & Quebec & Brasil & Quebec \\
\hline $1^{\circ}$ ano & 98,5 & 100 & 1,5 & 0 \\
\hline $2^{\circ}$ ano & 94,9 & 100 & 5,1 & 0 \\
\hline $3^{\circ}$ ano & 81,7 & 95,2 & 18,3 & 4,8 \\
\hline $4^{\circ}$ ano & 78,2 & 97,6 & 21,8 & 2,4 \\
\hline $5^{\circ}$ ano & 81,5 & 79,3 & 18,5 & 20,7 \\
\hline
\end{tabular}

Fonte: Dados da pesquisa.

Na Figura 11, apresentamos um exemplo de atividade com tabela de dupla entrada, na qual é mostrada a quantidade de alunos praticantes da modalidade esportiva de atletismo e de ginástica, durante o período de 2012 a 2015.

Figura 11 - Exemplo de representação em Tabela de dupla entrada

3 Copie em seu caderno a tabela abaixo, referente ao número de habitantes de um municipio, e complete-a. Depois, responda às questões no caderno.

\begin{tabular}{|l|c|c|c|}
\hline \multicolumn{4}{|c|}{ Habitantes do município } \\
\hline Idade Gênero & Homens & Mulheres & Total ODE \\
\hline Até 18 anos & 1724 & 1836 & 3560 \\
\hline Maiores de 18 anos & 2465 & 1539 & 4004 \\
\hline Total & 4189 & 3375 & 7564 \\
\hline
\end{tabular}

a) Quantos habitantes há, ao todo, nesse municipio? 7564 habitantoe.

b) Há quantos homens a mais que mulheres nesse município? 814 homens.

c) Nesse município, quantas mulheres maiores de 18 anos há a menos que

homens maiores de 18 anos? 928 mutheres.

60 sessenta

Fonte: Coleção 4br, $5^{\circ}$ ano, p. 60

Os PCNs (Brasil, 1997) apontam para a leitura, interpretação e representação de dados em tabelas de dupla entrada desde o $1^{\circ}$ ciclo do Ensino Fundamento. No mesmo sentido, "Progression des apprentissages: Mathématique" (MELS, 2009) orienta que os alunos devem fazer pesquisas para responder perguntas e serem capazes de tirar conclusões, formular diferentes tipos de perguntas, determinar categorias ou escolhas de respostas, planejar e realizar coletas de dados e organizá-las usando tabelas em particular, que, por sua vez, podem envolver temas de pesquisa com mais de uma variável.

Parece-nos que tais orientações não estão sendo efetivamente cumpridas pelas propostas de atividades em livros didáticos dos anos iniciais do Ensino Fundamental, pois, como visto, essas são escassas. Tal situação foi vista também nos estudos de Díaz-Levicoy, Morales, López-Martín e Roa-Munóz (2015) e Salcedo (2020).

Em relação à categoria tipo de variável explorada na tabela, é possível observar (Quadro 7) que a maioria das atividades utiliza variável nominal, independente do ano de escolarização e do lugar de publicação das coleções. As variáveis ordinal, discreta e contínua também são encontradas, entretanto, muito timidamente e isso não ocorre em todos os anos escolares. Resultados semelhantes foram encontrados nos estudos de Díaz-Levicoy, Morales e López-Martín (2015), Cazorla, Magina, Gitirana e Guimarães (2017) e, ainda, DíazLevicoy, Vásquez e Molina-Portillo (2018).

Quadro 7 - Percentual de atividade por tipo de variável representada na tabela em função do ano escolar e lugar de publicação

\begin{tabular}{|c|c|c|c|c|c|c|c|c|}
\hline Variável & \multicolumn{2}{|c|}{ Nominal } & \multicolumn{2}{c|}{ Ordinal } & \multicolumn{2}{c|}{ Discreta } & \multicolumn{2}{c|}{ Contínua } \\
\hline Lugar Ano & BRA & QUE & BRA & QUE & BRA & QUE & BRA & QUE \\
\hline $1^{\circ}$ ano & 79,1 & 95,8 & 0 & 14,9 & 14,9 & 4,2 & 4,5 & 0 \\
\hline $2^{\circ}$ ano & 89,0 & 84,0 & 0 & 8,0 & 7,4 & 4,0 & 3,6 & 4,0 \\
\hline $3^{\circ}$ ano & 72,5 & 78,6 & 3,1 & 2,4 & 13,0 & 9,5 & 11,4 & 9,5 \\
\hline $4^{\circ}$ ano & 65,3 & 53,7 & 1,7 & 19,5 & 15,3 & 12,2 & 17,7 & 14,6 \\
\hline $5^{\circ}$ ano & 71,8 & 62,1 & 0,8 & 13,8 & 14,5 & 6,9 & 12,9 & 17,2 \\
\hline
\end{tabular}

Fonte: Dados da pesquisa.

Essa excessiva utilização de um tipo de variável pelas coleções de livros didáticos nos deixa bastante preocupadas, pois os alunos, desde os primeiros anos de escolarização, têm contato com diferentes unidades de medidas, as quais poderiam estar aparecendo nas tabelas. Da mesma forma, variáveis ordinais também poderiam ser exploradas como pequeno, médio e grande. Dessa forma, questionamos por que as atividades com tabelas não trabalham de forma mais 
igualitária tais variáveis, visto que, no contexto social, os alunos se deparam com dados que envolvem crescimento populacional, num período de tempo, renda familiar ou, até mesmo, satisfação sobre determinado produto ou serviço.

$\mathrm{Na}$ Figura 12, temos uma tabela simples com variável ordinal (qualitativa), a qual representa uma pesquisa de opinião sobre uma apresentação teatral assistida por um grupo de crianças. Na Figura 13, observamos uma tabela com variável discreta (quantitativa), na qual é representada a quantidade de pessoas com deficiência matriculadas em algumas escolas no período de 2013 a 2015.

Figura 12 - Exemplo de atividade com variável ordinal (qualitativa)

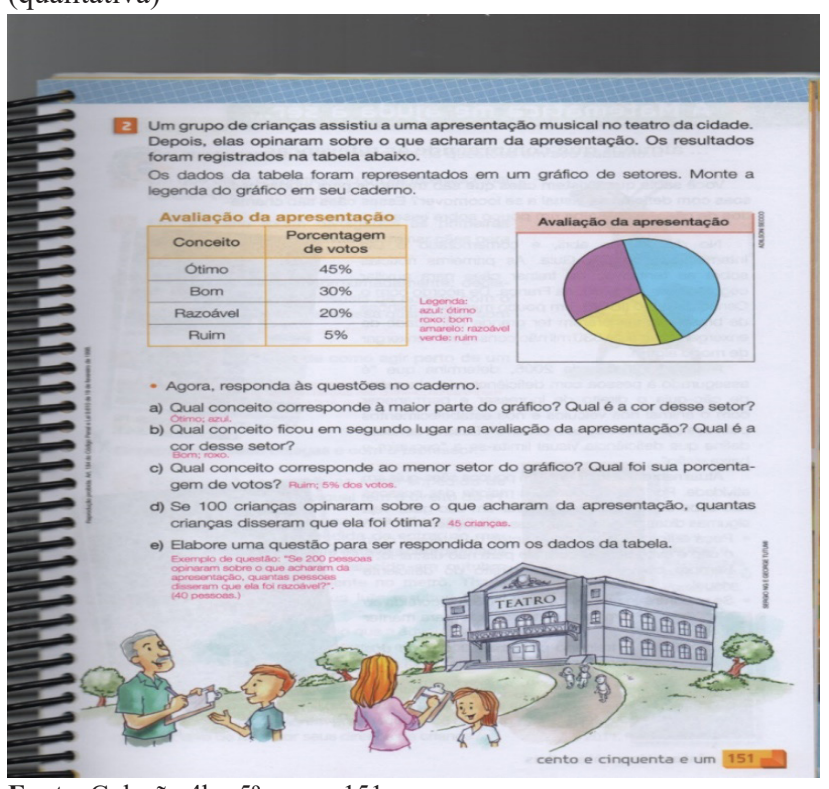

Fonte: Coleção 4br, $5^{\circ}$ ano, p.151

Figura 13 - Exemplo de atividade com variável discreta (quantitativa)

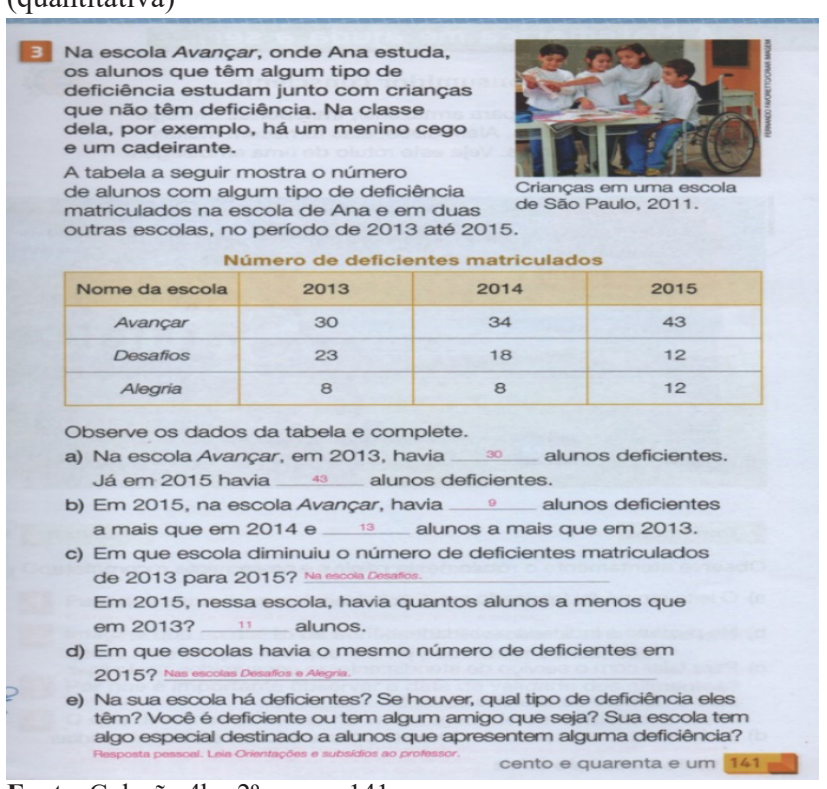

Fonte: Coleção 4br, $2^{\circ}$ ano, p. 141

Quanto à representação dos elementos fundamentais da tabela, nossa última categoria de análise, está apresentada no Quadro 8 na qual podemos observar uma preocupação dos autores de livros didáticos em colocar os elementos constituintes da tabela: título, apresentação de variáveis e fonte (reais e fictícias).

Quadro 8 - Percentual dos elementos fundamentais das tabelas por ano de escolarização e lugar de publicação

\begin{tabular}{|c|c|c|c|c|c|c|}
\hline \multirow{2}{*}{$\begin{array}{c}\text { Elementos } \\
\text { Lugar } \\
\text { Ano }\end{array}$} & \multicolumn{2}{|c|}{ Título } & \multicolumn{2}{|c|}{$\begin{array}{c}\text { Apresentação } \\
\text { de Variáveis }\end{array}$} & \multicolumn{2}{|c|}{ Fonte } \\
\hline & Brasil & Quebec & Brasil & Quebec & Brasil & Quebec \\
\hline $1^{\circ}$ ano & 41,8 & 100 & 91,0 & 100 & 43,3 & 0 \\
\hline $2^{\circ}$ ano & 80,9 & 76,0 & 98,5 & 100 & 42,6 & 0 \\
\hline $3^{\circ}$ ano & 80,9 & 92,9 & 97,7 & 100 & 58,0 & 2,4 \\
\hline $4^{\circ}$ ano & 88,7 & 95,1 & 97,6 & 100 & 54,8 & 0 \\
\hline $5^{\circ}$ ano & 91,1 & 58,1 & 100 & 100 & 58,9 & 17,2 \\
\hline
\end{tabular}

Observa-se que o título está ausente na maioria das tabelas apresentadas aos alunos do $1^{\circ}$ ano brasileiro. Estranhamente, os livros do Quebec também apresentam um baixo percentual em tabela do $5^{\circ}$ ano. Quanto à apresentação de variáveis, constatamos que as coleções de livros didáticos têm maior cuidado de apresentar esse elemento, pois quase todas as tabelas contêm nomes de variáveis/descritores, principalmente nas coleções do Quebec, que são 100\% nomeadas. O mesmo cuidado não podemos dizer das fontes das informações presentes nas tabelas das coleções didáticas brasileiras, uma vez que pouco mais da metade $(52,2 \%)$ das atividades apresenta referências sobre a fonte dos dados representados, independente delas serem reais ou fictícias. Menos ainda são apresentadas nos livros do Quebec, pois quase todas as atividades envolvendo tabelas $(96,3 \%)$ não informam a origem dos dados representados.

Isso nos faz refletir sobre que tipo de informações os alunos estão sendo levados a ter contato, porque elas são fictícias, "inventadas", o que contrasta com a ideia de que eles precisam aprender a analisar, questionar, levantar hipóteses, tirar conclusões ou a tomar decisões a partir de informações relevantes. Azcárate e Cardeñoso (2011) afirmam que o conhecimento estatístico deve ser visto como um conjunto de conceitos e técnicas que serão aplicadas dentro de um contexto que abraça cenários ou situações que possibilitam desenvolver diversas fases de uma abordagem estatística. Diante disso, deve-se entender esse conhecimento como algo aplicável em contextos reais, ou seja, para o entendimento da vida cotidiana.

\section{Considerações Finais}

Esse estudo buscou analisar atividades envolvendo tabelas apresentadas nos livros didáticos de Matemática dos anos iniciais do Ensino Fundamental do Brasil e do Quebec/ CA. Além disso, é necessário refletir sobre as propostas de ensino para a aprendizagem de tabelas encontradas em livros didáticos, utilizados por alunos dos anos iniciais do Ensino Fundamental do Brasil e do Quebec, uma vez que a tabela 
é uma representação que permite organizar e apresentar informações de forma rápida e resumida e seu uso, no cenário atual, é cada vez mais indispensável.

O ensino de tabelas, recomendado nos currículos de Matemática, aponta a necessidade de os alunos desenvolverem habilidades relacionas à coleta, organização, representação e análises dos dados apresentados em tabelas, com a finalidade de possibilitar julgamentos e tomadas decisões (Brasil, 1997). Dessa forma, acreditamos ser fundamental que os livros didáticos ofertem atividades que desenvolvam, nos alunos, a capacidade de se tornarem cidadãos letrados estatisticamente.

Foram analisados 50 livros didáticos brasileiros de Matemática e 20 livros do Quebec do $1^{\circ}$ ao $5^{\circ}$ do ano do Ensino Fundamental. Constatamos que em todos os anos e em ambos os lugares das publicações, são encontradas atividades que exploram os três tipos de representações apontados por Guimarães e Oliveira (2014), quadro, banco de dados e tabela. A representação quadro é a menos explorada pelos livros didáticos do Quebec e, principalmente, pelos do Brasil. Já a representação banco de dados é encontrada em todos os anos nos dois locais, mas, em ambos, não são nomeadas como tal, o que leva a uma indiferenciação de suas especificidades para os alunos. Os bancos de dados são denominados, em sua maioria, de tabelas ou, simplesmente, não são nomeados. Tal situação não é exclusiva das coleções analisadas por nós, tendo em vista que a literatura já relatava tais situações (Curi \& Nascimento, 2016; Guimarães \& Oliveira, 2014; Amorim \& Silva, 2016; Amorim \& Guimarães, 2016; Evangelista \& Guimarães, 2017; 2019).

Já as representações tabelas são, de fato, as mais exploradas pelos livros didáticos do Brasil e do Quebec. Encontramos atividades em que elas são utilizadas para focar outros conteúdos, principalmente nos últimos anos de escolarização, entretanto, a maioria das atividades foca a tabela como objeto de ensino. Esses resultados precisam ser ressaltados, uma vez que demonstram um avanço em comparação a outros encontrados nos estudos Pereira e Conti (2011), Curi e Nascimento (2016), Amorim e Silva (2016) que afirmam ter encontrado poucas atividades com tabelas como foco de ensino.

Entretanto, as atividades que têm a tabela como objeto de ensino, ainda priorizam as habilidades de interpretar dados sem uma preocupação com as conclusões possíveis para uma tomada de decisão em função deles e, em relação a construção, a maioria envolve preencher ou transpor informações entre representações nas quais as tabelas já estão estruturadas.

Por fim, destacamos, também, a pouca preocupação dos livros didáticos em não indicar as fontes das informações presentes nas tabelas, principalmente nas atividades dos manuais do Quebec, pois, em quase sua totalidade, não apresenta qualquer indicativo de onde as informações foram extraídas. Isso se deve ao fato de que as situações representadas nas tabelas foram "inventadas" pelos autores dos livros, os quais não se preocuparam em sinalizar a fonte. Porém, essa é um dos elementos da confiabilidade de uma pesquisa.

Defendemos que os alunos precisam e devem ser levados a explorar informações da sua realidade sociocultural, com intuito de entendê-las e usá-las de forma mais pertinente. Conforme Gal (2002), a alfabetização estatística é uma habilidade fundamental que os cidadãos precisam ter em função das constantes informações que circulam na sociedade, as quais têm como base a capacidade de interpretar, avaliar criticamente, além de comunicar informações e mensagens estatísticas.

\section{Agradecimentos}

Este estudo foi financiado em parte pela Coordenação de Aperfeiçoamento de Pessoal de Nível Superior - Brasil (CAPES) em colaboração com a Université Laval no Quebec.

\section{Referências}

Amorim, N. D.; Guimarães, G. L. (2016). Estatística nos anos iniciais: o currículo prescrito nos guias do PNLD. In: Encontro Nacional de Educação Matemática. Anais do X ENEM. São Paulo. [Online: http://www.sbembrasil.org.br/ enem2016/anais/pdf/7007_3134_ID.pdf]

Amorim, N. D.; Silva, R. L. (2016). Apresentação e utilização de tabelas em livros didático de Matemática do $4^{\circ}$ E $5^{\circ}$ anos do Ensino Fundamental. Revista de Educação Matemática e Tecnologia Iberoamericana - Em Teia. https://periodicos. ufpe.br/revistas/emteia/article/view/3893]

Azcárete, P.; Cardenõso, J. M. (2011). La Enseñanza de la Estadística a través de Escenarios: implicación en el desarrollo professional. Bolema, 24 (40), 789-810,

Bivar, D. \& Selva, A. (2013). Como as crianças constroem tabelas? Anais do $3^{\circ}$ SIPEMAT - Simpósio Internacional de pesquisa em Educação Matemática. Ilhéus, 2013. [Online:http:// proativa.virtual.ufc.br/sipemat2012/papers/600/submission/ director/600.pdf

Bivar, D, \& Selva, A. (2011). Analisando atividades envolvendo gráficos e tabelas nos livros didáticos de matemática. Anais da XIII CIAEM - Conferência Interamericana de Educação Matemática. Recife. [Online:https:/ciaem-redumate.org/ocs/ index.php/xiii_ciaem/xiii_ciaem/paper/view/1332/843]

Brasil. (1997). Parâmetros Curriculares Nacionais. $1^{\mathrm{a}}$ a $4^{\mathrm{a}}$ série. Brasília: MEC/SEF

Brasil. (2015). Guia de livros didáticos: PNLD 2016: Alfabetização Matemática e Matemática. Secretaria de Educação Básica. Brasília: MEC.

Brasil. (2018). Base Nacional Comum Curricular. Brasília: MEC.

Cazorla, I. Magina, S., Gitirana, V. \& Guimarães, G. (2017). Estatística para os anos iniciais do Ensino Fundamental. Brasília: SBEM.

Conti, K. \& Carvalho, D. (2011), O letramento presente na construção de tabelas por alunos da Educação de Jovens e Adultos. Boletim de Educação Matemática, 24 (20), 637-658. [Online: http://www.redalyc.org/pdf/2912/291222113002. pdf]

Curi, E. \& Nascimento, J. (2016). O trabalho com gráficos e tabelas nos currículos prescritos, apresentados, praticados e avaliados. ENCEPAI - Encontro de Combinatório, Estatísticas e Probabilidade dos anos iniciais. Recife. [online:http://anaisencepai.edumatec.net/index.php/2016-02- 
24-19-44-28/comunicacoes-cientificas/item/o-trabalho-comgraficos-e-tabelas-nos-curriculos-prescritos-apresentadospraticados-e-avaliados]

Díaz-Levicoy, D., Morales, R.; López-Martín, M. M. (2015). Tablas estadísticas en libros de texto chilenos de $1^{\circ}$ y $2^{\circ}$ año de Educación Primaria. Revista Paranaense de Educação Matemática, 4(7), 10-39.

Díaz-Levicoy, D.; Morales, R.; Ortiz, C. V. (2017). Construcción de tablas estadísticas por estudiantes chilenos de tercero de Educación Primaría. Educação \& Linguagem, v. 20 n. 1, 149166.

Díaz-Levicoy, D.; Morales, R.; López-Martín, M. D. M.; RoaMuñoz, C. G. (2015). Tipos y niveles de lectura de tablas estadísticas en libros de texto de primeros cursos: un estudio en el contexto chileno. Comunicación presentada en III Congreso de Formación Inicial Docente: Buenas prácticas em le aula, Universidad de los Lagos. [online: https://www. researchgate.net/publication/283710871 Tipos y niveles de_lectura_de_tablas_estadisticas_en_libros_de_texto_de_ primeros_cursos_un_estudio_en_el_contexto_chileno]

Díaz-Levicoy, D.; Vásquez, C.; Molina-Portillo, E. (2018). Estudio exploratorio sobre tablas estadísticas en libros de texto de tercer año de educación primaria. Tangram - Revista de Educação Matemática, 1(2), 18-39.

Estrella, S.; Mena-Lorca, A.; Olfos, R. (2017). Naturaleza del objeto matemático "Tabla". magis, Revista Internacional de Investigación en Educación, 10 (20), 105-122. doi: https:// doi.org/10.11144/Javeriana.m10-20.nomt]

Estrella, S. (2014). El objeto tabla: un estudio epistemológico, cognitivo y didáctico. (Tesis doctoral no publicada). Pontificia Universidad Católica de Valparaíso: Chile.

Evangelista, B.; Guimarães, G. L. (2017). Tables in textbooks for elementary school grades 4 and 5. In: II International Conference on Mathematics Textbook Research and Development - ICMT, Rio de Janeiro. Anais do II ICMT.

Evangelista, B.; Guimarães, G. L. (2019). Análise de atividades sobre tabelas em livros didáticos brasileiros dos anos iniciais do Ensino Fundamental. En J. M. Contreras, M. M. Gea, M. M. López-Martín y E. Molina-Portillo (Eds.), Actas del Tercer Congreso Internacional Virtual de Educación Estadística.

Gabucio, F.; Martí, E.; Enfedaque, J.; Gilabert, S.; Konstantinidou, A. (2010). Níveles de comprensión de las tablas em alunos de primária y secundaria. Cultura y Educación, 22(2), 183-1987.

Gal, I. (2002). Adults'Statistical Literacy: Meanings, Components, Responsibilities. International Statistical Review. doi: https://doi.org/10.1111/j.1751-5823.2002.tb00336.x]

García-García, J. I.; D.; Vidal-Henry S.; Arredondo, E. H. (2019). Las tablas estadísticas en libros de texto de educación primaria en México. Revista Paradigma, 60 (2), 153-75.

Giot, B.; Quittre, V. (2008). Les tableaux à double entrée dans les écrits scientifiques des jeunes élèves. Cahiers des Sciences de l'Éducation - Université de Liège (aSPe). [Online : https:// orbi.uliege.be/bitstream/2268/13232/1/GIOT_QUITTRE_ CAH27-28_2008_103.pdf]

Guimarães, G. \& Gitirana, V. (2013). Estatística no Ensino Fundamental: a pesquisa como eixo estruturador. In: R.E., Borba, C. E., Monteiro. Processos de ensino e aprendizagem em Educação Matemática. UFPE.
Guimarães, G. L.; Oliveira, I. (2014). Construção e interpretação de gráficos e tabelas. In: Brasil. Pacto Nacional pela Alfabetização na Idade Certa, (PP.21-38). Brasília: MEC.

Guimarães. G, Gitirana. V., Cavalcante. M. \& Marques. M. (2007). Livros didáticos de Matemática nas séries iniciais: Análise das atividades sobre gráficos e tabelas. Anais do IX Encontro Nacional de Educação Matemática. Belo Horizonte.

Lahanier-Reuter. D. (2003). Lecture-écriture et gestion de tableaux. Les cahiers Theodile, 3, 83-98.

Martí, E.; Sedanio, E.; La Cerda, C. (2010). Alfabetización gráfica. La apropiación de las tablas como instrumentos cognitivos. Contextos, 9 (10), 65-78.

MELS. (2009). Progression des apprentissages: Mathématique. Québec. [Gouvernement du Québec].

MEQ. (2006). Programme de formation de l'école québécoise (MEQ, 2006). Québec. [Gouvernement du Québec]. Disponível em: http://www.education.gouv.qc.ca/ enseignants/pfeq/

Pallauta, J. D.; Serrano, M. M. G.; Guerrero, A. V. (2019). Las actividades sobre tablas estadísticas en textos escolares chilenos de educación básica. En J. M. Contreras, M. M. Gea, M. M. López-Martín y E. Molina-Portillo (Eds.), Actas del Tercer Congreso Internacional Virtual de Educación Estadística.

Pereira, R. F.; Conti, K. C. (2011). O Tratamento da Informação Presente em Livro Didático de Matemática do $5^{\circ}$ Ano do Ensino Fundamental. Revista Técnico-Científica das Faculdades Atibaia. V1.

Pontes, J. P.; Brocardo, J.; Oliveira, H. (2009). Investigações matemática na sala de aula. $2^{\mathrm{a}}$ edição. Belo Horizonte: Autêntica.

Pontes, M.; Guimarães, G. (2019). Construindo gráficos com auxílio do Excel nos anos iniciais do Ensino Fundamental. In: Encontro Nacional de Educação Matemática, Cuiabá. Anais do XIII Encontro Nacional de Educação Matemática. Brasília: SBEM.

Salcedo, A. (2020). Actividades de tablas esradísticas em textos escolares de matemáticas. Revista digital Matemática, Educación e Internet. 20(2)

Sepúlveda, A.; Díaz-Levicoy, D; Jara, D. (2018). Evaluación de la comprensión sobre Tablas Estadísticas en estudiantes de Educación Primaria Evaluation of the understanding on statistical tables in students of Elementary Education. Bolema, 32 (62), 869-86.

Silva, E.; Guimarães, G. (2013). Perspectivas para o ensino da educação estatística. In: Encontro Nacional de Educação Matemática. Anais do XI ENEM. Curitiba.

Vanegas, F. N. (2013). Consideraciones sobre la didáctica de la probabilidad y de La estadística. In: VII CIBEM - Congreso Iberoamericano de Educación Matemática. Anais do VII CIBEM. Montevideo. [Online: https://tecdigital. tec. ac.cr/revistamatematica/ARTICULOS_V19_N2_2019/ RevistaDigital_FNunez_V19_n2_2019/RevistaDigital_ $\mathrm{FNu} \% \mathrm{C} 3 \% \mathrm{~B} 1 \mathrm{ez}$ V19 n2 2019 .pdf] 